\title{
Excess mortality in a population with diabetes and the impact of material deprivation: longitudinal, population based study
}

\author{
Nick A Roper, Rudy W Bilous, William F Kelly, Nigel C Unwin, Vincent M Connolly
}

\begin{abstract}
Objectives To establish the age and sex specific mortality for people with diabetes in comparison with local and national background populations; to investigate the relationship between mortality and material deprivation in an unselected population with diabetes.

Design Longitudinal study, using a population based district diabetes register.

Setting South Tees, United Kingdom.

Participants All people known to have diabetes living in Middlesbrough and Redcar and Cleveland local authorities on 1 January 1994.

Main outcome measure Death, from any cause, between 1 January 1994 and 31 December 1999. Results Over the six years of the study $1205(24.9 \%)$ of 4842 participants died. All cause standardised mortality ratios for type 1 diabetes were 641 (95\% confidence interval 406 to 962) in women and 294 (200 to 418) in men, and those for type 2 diabetes were 160 (147 to 174 ) in women and 141 (130 to 152) in men. Cause specific standardised mortality ratios were increased for ischaemic heart disease, cerebrovascular disease, and renal disease; no reductions in mortality from other causes were seen. The risk of premature death increased significantly with increasing material deprivation $(\mathrm{P}<0.001)$.

Conclusions Diabetes is associated with excess mortality, even in an area with high background death rates from cardiovascular disease. This excess mortality is evident in all age groups, most pronounced in young people with type 1 diabetes, and exacerbated by material deprivation. Aggressive approaches to the management of cardiovascular risk factors could reduce the excess mortality in people with diabetes.
\end{abstract}

\section{Introduction}

Diabetes mellitus is known to be underreported on death certificates and hence underestimated by national mortality statistics. ${ }^{12}$ People with diabetes have been shown to have higher mortality than people without diabetes, but mortality varies depending on the location and the specific group studied. ${ }^{1-4}$ Mortality studies of unselected populations with diabetes have been performed in North America and Scandinavia. ${ }^{2}$ However, there is a paucity of British data referring to unselected populations and none from the north of England, an area with high mortality partly owing to higher levels of material deprivation. ${ }^{5}$ British studies of people with diabetes have shown increasing exposure to cardiovascular risk factors with worsening material deprivation, ${ }^{6-8}$ and data from people aged over 75 in the United Kingdom are unclear with regard to excess mortality and its possible causes. ${ }^{1910}$
Our study compared the mortality in people with known diabetes living in South Tees with the mortality of the population of England and Wales and the local population without diabetes. It also examined the relation between mortality and material deprivation in the population with diabetes.

\section{Methods}

The area administered by Middlesbrough and Redcar and Cleveland local authorities, referred to here as South Tees, had a population of 290000 in 1994. This area has high unemployment, and mortality is above the national average. ${ }^{11}$ Migration rates in the area are low: during the study less than 3\% of the cohort registered outside Tees Health Authority.

The cohort was derived from the South Tees district diabetes register and comprised all diabetic patients with an address in South Tees who were alive on 1 January 1994. The diabetes register is maintained by full time staff and contains demographic and clinical data on all people known to have diabetes. Data are collected prospectively from the adult and paediatric secondary care diabetes services, all primary care centres within the district, and the diabetes eye service. South Tees ethical committee granted approval for the study.

Analyses were undertaken for the population of people with diabetes as a whole and also for the population subdivided into type 1 and type 2 diabetes. The criteria for assigning type 1 diabetes were age 35 or less at diagnosis and receiving insulin treatment at the start of the study; the criteria for type 2 diabetes were age over 35 at diagnosis or not taking insulin.

\section{Death registration}

All participants were registered by the Office for National Statistics, and the date of death, causes of death, and underlying cause of death were obtained from death certificates for deaths occurring between 1 January 1994 and 31 December 1999 inclusive. The inconsistent inclusion of diabetes on death certificates creates problems when the underlying causes of death in groups with and without diabetes are compared. To correct for this a second underlying code for cause of death was derived in all cases where the underlying cause of death was diabetes-ICD-9 (international classification of disease, ninth revision) code 250-by removing diabetes from the list of causes and recoding the underlying cause of death using ICD-9 rules. Diabetes remained the underlying cause of death if it was the only listed cause or if the immediate cause of death was a short term metabolic complication, such as hypoglycaemia or ketoacidosis.

\section{Participants}

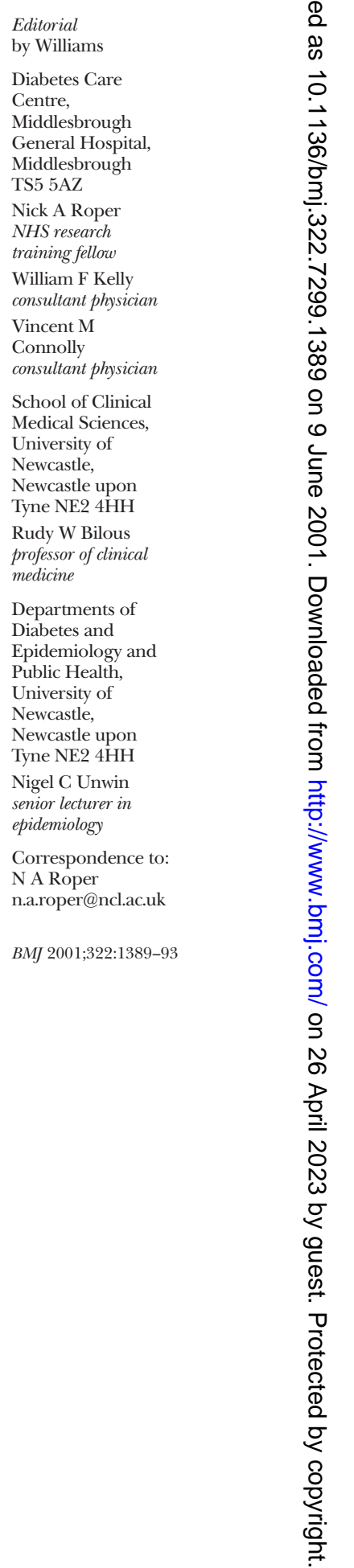


Table 1 Demographic data for the cohort at entry to study. Standardised prevalences shown are directly standardised by age to the combined populations of England and Wales, 1994-8

\begin{tabular}{|c|c|c|c|c|c|c|}
\hline \multirow[b]{2}{*}{$\begin{array}{l}\text { Age band (years) } \\
\text { and sex }\end{array}$} & \multicolumn{2}{|c|}{ Full cohort } & \multicolumn{2}{|c|}{ Type 1 diabetes } & \multicolumn{2}{|c|}{ Type 2 diabetes } \\
\hline & No & $\begin{array}{c}\text { Prevalence } \\
(\%)\end{array}$ & No & $\begin{array}{c}\text { Prevalence } \\
(\%)\end{array}$ & No & $\begin{array}{c}\text { Prevalence } \\
(\%)\end{array}$ \\
\hline \multicolumn{7}{|l|}{0 to 19 : } \\
\hline Female & 65 & 0.16 & 62 & 0.16 & 3 & 0.01 \\
\hline Male & 68 & 0.16 & 65 & 0.16 & 3 & 0.01 \\
\hline \multicolumn{7}{|l|}{20 to $39:$} \\
\hline Female & 244 & 0.58 & 168 & 0.40 & 76 & 0.18 \\
\hline Male & 292 & 0.69 & 221 & 0.52 & 71 & 0.17 \\
\hline \multicolumn{7}{|l|}{40 to $59:$} \\
\hline Female & 560 & 1.63 & 96 & 0.28 & 464 & 1.35 \\
\hline Male & 866 & 2.55 & 117 & 0.34 & 749 & 2.21 \\
\hline \multicolumn{7}{|l|}{60 to $79:$} \\
\hline Female & 1046 & 4.04 & 9 & 0.03 & 1037 & 4.01 \\
\hline Male & 1320 & 6.14 & 23 & 0.11 & 1297 & 6.03 \\
\hline \multicolumn{7}{|l|}{80 and over: } \\
\hline Female & 250 & 3.94 & 0 & 0 & 250 & 3.94 \\
\hline Male & 131 & 5.16 & 0 & 0 & 131 & 5.16 \\
\hline \multicolumn{7}{|l|}{ All ages: } \\
\hline Female & 2165 & 1.46 & 335 & 0.23 & 1830 & 1.24 \\
\hline Male & 2677 & 1.89 & 426 & 0.30 & 2251 & 1.59 \\
\hline \multicolumn{7}{|c|}{ Prevalence standardised by age (\%) } \\
\hline Female & & 1.53 & & 0.23 & & 1.31 \\
\hline Male & & 1.96 & & 0.30 & & 1.65 \\
\hline Combined & & 1.74 & & 0.26 & & 1.48 \\
\hline
\end{tabular}

\section{Comparison populations}

Most studies of mortality related to diabetes use whole population data as the comparator, despite the fact that these data include people with diabetes, leading to bias in the estimated effect. This bias can be considerable when the prevalence of diabetes is high or the standardised mortality ratio is large. ${ }^{12}$ Using local data and removing people known to have diabetes from the comparison group should minimise this bias.

The national comparison was made by using population and mortality data for England and Wales, 1994-8. ${ }^{11}$ The local comparison was made with the population of South Tees without known diabetes. This population was derived by removing people known to have diabetes from population figures for each year obtained from the Tees Valley Joint Strategy Unit. Mortality data were calculated by removing deaths of those known to have diabetes from the full local mortality data obtained from Office for National Statistics VS3 returns for South Tees, 1994-9, provided by Tees Health Authority. Deaths were matched by year of death, sex, five year age band, and cause of death (for cause specific analyses) and were adjusted for the decline in cohort numbers each year.

\section{Material deprivation}

Postcodes were used to allocate each participant to a 1991 census enumeration district, and a Townsend score was generated for each district as a measure of material deprivation. ${ }^{13}$ Participants were then grouped into fifths by their score.

Analysis

Mortality was compared by using standardised mortality ratios, with both the local and national populations described above as reference populations. Calculation of confidence intervals for standardised mortality ratios was based on the assumption that the observed number of deaths is the mean of a Poisson distribution, upper and lower 95\% limits for which can be obtained from published tables. ${ }^{14}$ Dividing these limits by the expected number of deaths and multiplying by 100 produces $95 \%$ confidence intervals for the standardised mortality ratio. Similarly, 95\% confidence intervals for death rates standardised for age were estimated by using the formula

observed death rate $\pm(1.96 \times$ observed death rate/ Vobserved number of deaths).

Division by the death rate in the reference population produced the corresponding confidence intervals for the relative rates. The hypothesis that the risk of dying during the study increased with worsening material deprivation was tested by using $\chi^{2}$ for linear trend across the Townsend fifths.

A life table approach, based on published Office for National Statistics data, ${ }^{15}{ }^{16}$ was used to model the average life expectancy subject to either the death rates in the study for people with type 2 diabetes or the average death rates of England and Wales between 1994 and 1997. The reduction in life expectancy is then the life expectancy calculated using the national death rates minus the life expectancy calculated using the death rates for people with diabetes.

\section{Results}

The cohort comprised 4842 people, giving 25610 person years of follow up. Table 1 gives demographic information. Only 22 subjects $(0.45 \%)$ could not be traced. Overall, 1205 participants died (24.9\%)-659 men $(24.6 \%)$ and 546 women (25.2\%). Diabetes was certified as the underlying cause of death for $9.4 \%$ of men and $11.9 \%$ of women and was mentioned on the death certificates of $45.4 \%$ of men and $50.6 \%$ of women.

The data for all cause mortality (table 2) showed excess deaths in patients with type 1 and type 2 diabetes in both sexes at all ages. Without exception, the excess was higher in comparison with the national population than with the local population without diabetes, reflecting the higher than national mortality in South Tees. ${ }^{11}$

This cohort had significant excess mortality from cardiovascular disease, ischaemic heart disease, cerebrovascular disease, and renal disease, but mortality from neoplasia, respiratory disease, or accidents and poisonings was not reduced (table 3). The risk of death during the study in the most affluent fifth with diabetes is in excess of that in the local population without diabetes (table 4), and the risk rises significantly with worsening material deprivation.

The life table analyses (figure) show that, potentially, the life expectancy of both men and women diagnosed as having type 2 diabetes at age 40 is reduced by eight years relative to people without diabetes. For those whose diagnosis was made after the age of 50 , women can expect to lose more years than men, although the difference begins to narrow over the age of 70 . If the mortality of those aged under 80 had been at national rates then 430 of the 1205 deaths would have been avoided during the six years studied. 
Table 2 All cause mortality in cohort with diabetes compared with the local population without diabetes, 1994-9, and the population of England and Wales, 1994-8

Type 1 diabetes Standardised mortality ratio $(95 \% \mathrm{Cl})^{\star}$

Age at death (years) and sex 0-39:

\begin{tabular}{|c|c|c|c|c|c|c|}
\hline Female & 3 & 515 (106 to 1505) & 526 (109 to 1538) & 2 & Not determined & Not determined \\
\hline Male & 4 & 273 (75 to 700$)$ & 288 (79 to 738 ) & 1 & Not determined & Not determined \\
\hline \multicolumn{7}{|l|}{ 40-59: } \\
\hline Female & 11 & 620 (309 to 1109) & 707 (353 to 1265) & 24 & 256 (164 to 381 ) & 298 (191 to 443) \\
\hline Male & 16 & 421 (241 to 684 ) & 497 (284 to 806) & 73 & 314 (246 to 395$)$ & 371 (291 to 466) \\
\hline \multicolumn{7}{|l|}{ 60-79: } \\
\hline Female & 9 & 730 (334 to 1387$)$ & 848 (388 to 1610$)$ & 279 & 196 (173 to 220 ) & 223 (197 to 250 ) \\
\hline Male & 9 & 172 (79 to 327$)$ & 202 (92 to 384$)$ & 411 & 141 (128 to 155$)$ & 164 (148 to 180$)$ \\
\hline \multicolumn{7}{|c|}{80 and over: } \\
\hline Female & 0 & Not determined & Not determined & 218 & 125 (109 to 142$)$ & 126 (110 to 144$)$ \\
\hline Male & 2 & Not determined & Not determined & 143 & 109 (92 to 129) & 116 (98 to 136) \\
\hline \multicolumn{7}{|l|}{ All ages: } \\
\hline Female & 23 & 641 (406 to 962) & 722 (458 to 1083 ) & 523 & 160 (147 to 174$)$ & 171 (156 to 186$)$ \\
\hline Male & 31 & 294 (200 to 418 ) & 340 (231 to 483 ) & 628 & 141 (130 to 152$)$ & 159 (147 to 172$)$ \\
\hline
\end{tabular}

*Standardised mortality ratio shown only for categories in which three or more deaths occurred.

\section{Discussion}

This study shows an excess mortality associated with diabetes, even in an area with high background death rates from cardiovascular disease. This excess mortality is evident in all age groups, is most pronounced in young people with type 1 diabetes, and is exacerbated by material deprivation.

The large number of people studied, the almost complete follow up, and the linkage to Office for National Statistics records enabled us to draw conclusions with confidence. Use of the local population without diabetes as the comparison group minimised bias in the estimates of relative mortality, and the observed differences between local and national comparisons emphasised the importance of using local data for comparisons where possible. We believe that our method of recoding the cause of death allowed for more meaningful comparisons of cause specific mortality between the groups with and without diabetes.

Owing to the methods used to collate the register it was not possible to perform capture-recapture analysis to estimate ascertainment, but we are confident that the data collection methods will have included most of the local population known to have diabetes and that no particular groups have been systematically excluded. Our prevalence data (table 1) are comparable to previously reported prevalences of between $1 \%$ and $1.71 \%$ in the United Kingdom. ${ }^{417}$ The definitions of type of diabetes used are based on epidemiological rather than clinical criteria but are similar to those used in previous studies and are therefore suitable for comparison. ${ }^{17}{ }^{18}$ The relatively small number of deaths in people aged under 40 result in wide confidence intervals in some subgroups. The estimated standardised mortality ratios are, however, similar to previous estimates from the United States and are higher than recent British estimates derived from selected groups. ${ }^{19}{ }^{20}$ The national comparison group includes people with diabetes in the reference population, which is a potential source of bias, and thus our results will underestimate any excess in mortality.
The deprivation analyses rely on assigning an index (the Townsend score) at a group level (the enumeration district) and applying this to individuals, assuming that all people in the group have similar deprivation levels - an example of the "ecological fallacy." However, the methodology is well established, ${ }^{6-8}$ and bias from misclassification between deprivation fifths would be likely to mask any observed differences.

We believe that our study provides accurate and comprehensive data on the excess mortality associated with diabetes in the United Kingdom, which extends and updates previous data that mainly relate to

Table 3 Cause specific mortality in cohort with diabetes compared with the local population without diabetes, 1994-9

\begin{tabular}{|c|c|c|c|c|}
\hline \multirow[b]{2}{*}{ Cause (ICD-9 code) and sex } & \multicolumn{2}{|r|}{ Type 1 diabetes } & \multicolumn{2}{|r|}{ Type 2 diabetes } \\
\hline & $\begin{array}{l}\text { No of } \\
\text { deaths }\end{array}$ & $\begin{array}{l}\text { Standardised mortality } \\
\text { ratio }(95 \% \mathrm{Cl})^{\star}\end{array}$ & $\begin{array}{l}\text { No of } \\
\text { deaths }\end{array}$ & $\begin{array}{l}\text { Standardised mortality } \\
\text { ratio }(95 \% \mathrm{Cl})^{*}\end{array}$ \\
\hline \multicolumn{5}{|l|}{$\begin{array}{l}\text { Cardiovascular causes } \\
\text { (390-459): }\end{array}$} \\
\hline Female & 13 & 1365 (727 to 2334) & 317 & 226 (202 to 253) \\
\hline Male & 21 & 536 (332 to 819) & 370 & 196 (177 to 217) \\
\hline \multicolumn{5}{|l|}{$\begin{array}{l}\text { Ischaemic heart disease } \\
(410-414)\end{array}$} \\
\hline Female & 9 & 1814 (829 to 3443 ) & 200 & 268 (232 to 307$)$ \\
\hline Male & 19 & 686 (413 to 1071$)$ & 273 & 223 (198 to 251) \\
\hline
\end{tabular}

\section{Cerebrovascular disease}

(430-438)

\begin{tabular}{llcll}
\hline Female & 3 & 1146 (236 to 3348) & 80 & 191 (151 to 238) \\
\hline Male & 1 & Not determined & 67 & 180 (139 to 229) \\
\hline
\end{tabular}

Nephritis, nephrotic syndrome,

and nephrosis (580-589)

\begin{tabular}{|c|c|c|c|c|}
\hline Female & 1 & Not determined & 7 & 289 (116 to 596$)$ \\
\hline Male & 1 & Not determined & 11 & 461 (230 to 826$)$ \\
\hline \multicolumn{5}{|c|}{ Neoplasia (140-239) } \\
\hline Female & 2 & Not determined & 75 & 98 (77 to 123) \\
\hline Male & 0 & Not determined & 133 & 95 (79 to 112$)$ \\
\hline \multicolumn{5}{|c|}{ Respiratory disease (460-519) } \\
\hline Female & 3 & 953 (197 to 2786 ) & 61 & 98 (75 to 126$)$ \\
\hline Male & 3 & 300 (62 to 878$)$ & 71 & 101 (79 to 127$)$ \\
\hline
\end{tabular}

Accidents and poisonings

(E800-E999)

\begin{tabular}{lllrl}
\hline Female & 0 & Not determined & 4 & 119 (32 to 304) \\
\hline Male & 1 & Not determined & 11 & 169 (84 to 302) \\
\hline
\end{tabular}

* Standardised mortality ratio shown only for categories in which three or more deaths occurred. 
Table 4 Deaths during the study, by Townsend fifth of material deprivation, types of diabetes combined, and median age (interquartile range) at start of study

\begin{tabular}{|c|c|c|c|c|c|c|}
\hline & \multicolumn{5}{|c|}{ Fifth of material deprivation } & \multirow{2}{*}{$\begin{array}{l}\chi^{2} \text { for } \\
\text { trend }\end{array}$} \\
\hline & 1 (most deprived) & 2 & 3 & 4 & 5 (most affluent) & \\
\hline \multicolumn{7}{|l|}{ Women: } \\
\hline No & 446 & 443 & 432 & 394 & 412 & \multirow{4}{*}{$P=0.00$} \\
\hline Age & $62(50-71)$ & $64(51-74)$ & $64(51-74)$ & $64(52-73)$ & $63(47-73)$ & \\
\hline Deaths (\% of fifth) & $126(28.3)$ & $117(26.4)$ & $119(27.5)$ & $94(23.9)$ & $82(19.9)$ & \\
\hline Relative death rate $(95 \% \mathrm{Cl})^{*}$ & 2.07 (1.71 to 2.43 ) & 2.05 (1.68 to 2.43 ) & $1.43(1.17$ to 1.68$)$ & $1.41(1.12$ to 1.69$)$ & $1.19(0.93$ to 1.45$)$ & \\
\hline \multicolumn{7}{|l|}{ Men: } \\
\hline No & 505 & 513 & 517 & 562 & 536 & \multirow{4}{*}{$P<0.001$} \\
\hline Age & $60(47-68)$ & $62(51-69)$ & $62(52-69)$ & $62(51-71)$ & $60(48-69)$ & \\
\hline Deaths (\% of fifth) & $140(27.7)$ & $144(28.1)$ & $136(26.3)$ & $127(22.6)$ & $102(19.0)$ & \\
\hline Relative death rate $(95 \% \mathrm{Cl})^{*}$ & 2.49 (2.08 to 2.91$)$ & 2.41 (2.02 to 2.80$)$ & 2.05 (1.70 to 2.39 ) & 1.64 (1.36 to 1.93$)$ & 1.47 (1.19 to 1.76$)$ & \\
\hline \multicolumn{7}{|l|}{ Both sexes: } \\
\hline No & 951 & 956 & 949 & 956 & 948 & \multirow{4}{*}{$P<0.00$} \\
\hline Age & $61(48-69)$ & $63(51-72)$ & $63(52-71)$ & $62(52-72)$ & $61(48-71)$ & \\
\hline Deaths (\% of fifth) & $266(28.0)$ & $261(27.3)$ & $255(26.9)$ & $221(23.1)$ & $184(19.4)$ & \\
\hline Relative death rate $(95 \% \mathrm{Cl})^{*}$ & 2.34 (2.05 to 2.62$)$ & 2.24 (1.96 to 2.51$)$ & $1.70(1.50$ to 1.91$)$ & 1.52 (1.32 to 1.72$)$ & 1.30 (1.11 to 1.49$)$ & \\
\hline
\end{tabular}

*Study death rates, directly standardised by age to the combined male and female local population without diabetes, relative to the death rate of the same population.

primary care, ${ }^{4}$ secondary care, ${ }^{921}$ or patients treated with insulin. ${ }^{121}$ The study also shows that excess mortality exists even against a background of high levels of material deprivation and high mortality. Moreover, the most affluent fifth with diabetes still had a higher mortality than the local population without diabetes, and this excess mortality rises progressively with worsening material deprivation. These data extend the previous British data on the impact of socioeconomic factors on mortality related to diabetes, which described only patients treated in hospital or selected middle aged patients. ${ }^{22}{ }^{23}$ The excess mortality extends even to those aged 80 and over, and the observed increased death rate from cardiovascular causes in all ages is not compensated for by a reduction in other major causes of death.

\section{Conclusions}

In 1990 the St Vincent declaration recommended targets for care of patients with diabetes, including the general goal of "a life approaching normal expectation

\section{What is already known on this topic}

Mortality, mainly from cardiovascular disease, is increased in people with diabetes, but this excess varies considerably by country and ethnic group

Previous British studies have reported no excess mortality in old age, a reduction in deaths from non-cardiovascular causes, and that mortality may be adversely affected by deprivation

\section{What this study adds}

Mortality is increased, across all ages, in an unselected population with diabetes compared with the local population without diabetes, which itself has high mortality

Most of the excess is from cardiovascular causes, but there are no reductions in other causes of death

Mortality among people with diabetes is increased even in the most affluent group, and this excess increases with worsening material deprivation

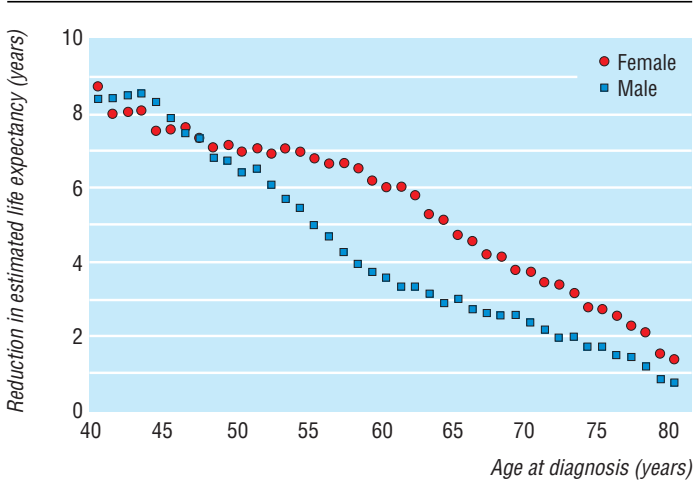

Reductions in estimated life expectancy, by age at diagnosis of type 2 diabetes

in quality and quantity."24 Unfortunately, the results from this study show that we are still far from this ideal.

The main cause of death in our cohort with diabetes was ischaemic heart disease. The national service framework for coronary heart disease has set national targets and standards for the prevention and treatment of coronary heart disease. ${ }^{25}$ The forthcoming national service framework for diabetes will provide a further opportunity to reduce the risk of premature death in our patients. We believe that our data will help to inform this process and that they underline the importance of material deprivation. Aggressive approaches to the management of cardiovascular risk factors could reduce the excess mortality in people with diabetes.

We thank Clare Eynon, research and information officer at Tees Health, for providing local population and mortality data; Keith Elliott, principal information officer at Tees Valley Joint Strategy Unit, for providing the Townsend score data; Pam Sherriff, Elaine Hall, Dan Bowes, and all the other staff at the Diabetes Centre for collating and maintaining the diabetes register, and all the clinical staff in primary and secondary care without whose cooperation the diabetes register would not be viable.

Contributors: VMC, WFK, and NCU had the original idea for the study and set up the initial cohort tagging. The study design was adapted and developed in collaboration with NAR and RWB. NAR performed the main data collection and drafted the paper. NAR, VMC, and NCU performed the data analysis. 
All the authors contributed to the review and writing of the paper. NAR and VMC will act as guarantors of the paper.

Funding: The original cohort tagging was funded by a grant from Diabetes UK, formerly the British Diabetic Association. NAR is funded by the NHS Executive, Northern and Yorkshire Region.

Competing interests: None declared.

1 Raymond NT, Langley JD, Goyder E, Botha JL, Burden AC, Hearnshaw JR. Insulin treated diabetes mellitus: causes of death determined from record linkage of population based registers in Leicestershire, UK. J Epidemiol Community Health 1995;49:570-4.

$2 \mathrm{Gu} \mathrm{K}$, Cowie CC, Harris MI. Mortality in adults with and without diabetes in a national cohort of the US population, 1971-1993. Diabetes Care 1998;21:1138-45.

3 Koskinen SV, Reunanen AR, Martelin TP, Valkonen T. Mortality in a large population-based cohort of patients with drug-treated diabetes mellitus. Am J Public Health 1998;88:765-70.

4 Gatling W, Tufail S, Mullee MA, Westacott TA, Hill RD. Mortality rates in diabetic patients from a community-based population compared to local age/sex matched controls. Diabet Med 1997;14:316-20.

5 Phillimore P, Beattie A, Townsend P. Widening inequality of health in northern England, 1981-91. BMJ 1994;308:1125-8.

6 Unwin N, Binns D, Elliott K, Kelly WF. The relationships between cardiovascular risk factors and socio-economic status in people with diabetes Diabet Med 1996;13:72-9.

7 Kelly WF, Mahmood R, Kelly MJ, Turner S, Elliott K. Influence of social deprivation on illness in diabetic patients. BMJ 1993;307:1115-6.

8 Connolly VM, Kesson CM. Socioeconomic status and clustering of cardiovascular disease risk factors in diabetic patients. Diabetes Car $1996 ; 19: 419-22$

9 Wong JS, Pearson DW, Murchison LE, Williams MJ, Narayan V. Mortality in diabetes mellitus: experience of a geographically defined population. Diabet Med 1991;8:135-9.

10 Croxson SC, Price DE, Burden M, Jagger C, Burden AC. The mortality of elderly people with diabetes. Diabet Med 1994;11:250-2

11 Office of Population Censuses and Surveys. Mortality statistics: cause London: Stationery Office, 1994-1999. (Series DH2, Nos 21-26.)
12 Jones ME, Swerdlow AJ. Bias in the standardized mortality ratio when using general population rates to estimate expected number of deaths. Am J Epidemiol 1998;148:1012-7.

13 Townsend P, Phillimore P, Beattie A. Health and deprivation:inequality in the north. London: Croom Helm, 1988.

14 Documenta Geigy. Scientific tables. Basle, Switzerland:JR Geigy SA, 1970.

15 Office of Population Censuses and Surveys. Mortality statistics. London: Stationery Office, 1994-1997. (Series DH1, Nos 27-30.)

16 Devis T. The expectation of life in England and Wales. Population Trend 1990;60:23-4.

17 Evans JMM, Newton RW, Ruta DA, MacDonald TM, Morris AD Socio-economic status, obesity and prevalence of type 1 and type 2 diabetes mellitus. Diabet Med 2000;17:478-80.

18 Muggeo M, Verlato G, Bonora E, Bressan F, Girotto S, Corbellini M, et al The Verona diabetes study: a population-based survey on known diabetes mellitus prevalence and 5-year all-cause mortality. Diabetologia 1995;38:318-25.

19 Moss SE, Klein R, Klein BE. Cause-specific mortality in a populationbased study of diabetes. Am J Public Health 1991;81:1158-62.

20 Laing SP, Swerdlow AJ, Slater SD, Bothat JL, Burden AC, Waugh NR, et al. The British Diabetic Association cohort study, I: all-cause mortality in patients with insulin-treated diabetes mellitus. Diabet Med 1999;16: 459-65.

21 Waugh NR, Dallas JH, Jung RT, Newton RW. Mortality in a cohort of diabetic patients. Causes and relative risks. Diabetologia 1989;32:103-4.

22 Robinson N, Lloyd CE, Stevens LK. Social deprivation and mortality in adults with diabetes mellitus. Diabet Med 1998;15:205-12.

23 Chaturvedi N, Jarrett J, Shipley MJ, Fuller JH. Socioeconomic gradient in morbidity and mortality in people with diabetes: cohort study finding from the Whitehall study and the WHO multinational study of vascular disease in diabetes. BMJ 1998;316:100-5.

24 Diabetes care and research in Europe: the Saint Vincent Declaration. Diabet Med 1990;7:360.

25 Department of Health. National service framework for coronary heart disease. Modern standards and service models. London: Stationery Office, 2000.

(Accepted 8 March 2001)
Defibrillation is necessary to restore normal sinus rhythm in a patient having a ventricular fibrillation arrest. Each minute of delay in restoring sinus rhythm increases mortality by $7-10 \% .{ }^{1}$ Successful defibrillation requires depolarisation of a critical mass of myocardium, which is most likely to be achieved if the defibrillation paddles are correctly placed. Recent guidelines from the European Resuscitation Council state that the sternal paddle should be placed "below the right clavicle in the mid-clavicular line" and that the apical paddle should be placed "over the left lower ribs in the mid/anterior axillary line." 2 The limited literature available and our own observations suggest that these anatomical positions are not adhered to during defibrillation. ${ }^{3}$ We undertook an observational study to assess paddle positioning during defibrillation.

\section{Methods and results}

We recruited 101 doctors of all grades and acute specialties at Southampton General Hospital over a period of two weeks, who were unprepared and unaware of the nature of the study. They were shown an anatomically accurate male resuscitation manikin that they were told was in ventricular fibrillation. They were asked to defibrillate the manikin, which required the initial placement of sternal and apical defibrillation pads on the chest wall, on to which were placed the

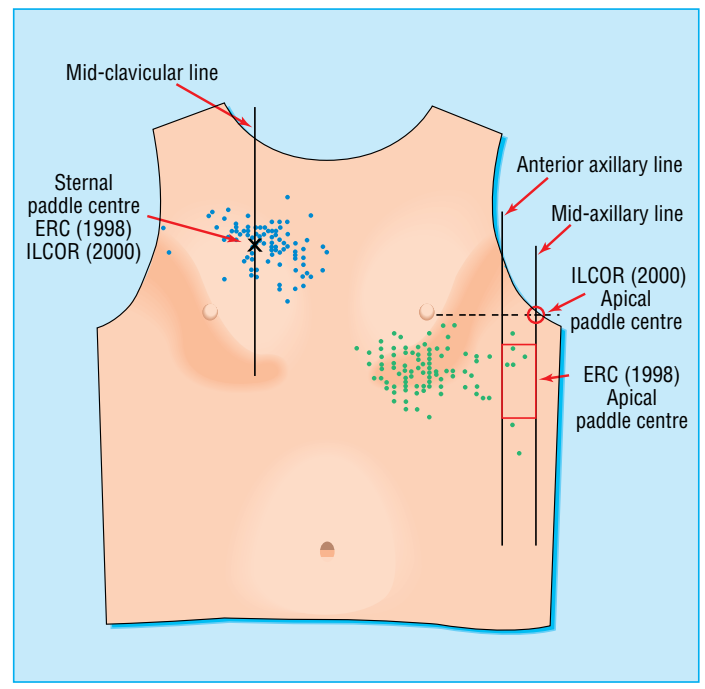

Shackleton Department of Anaesthetics, Southampton General Hospital NHS Trust, Southampton SO16 6YD Richard M Heames specialist registrar Daniel Sado medical student Charles D Deakin consultant anaesthetist

Correspondence to: C D Deakin cddeakin@ hotmail.com

BMJ 2001;322:1393-4

Anatomical position of the centre of apical and sternal defibrillation paddles placed by 101 doctors. Positions recommended by the European Resuscitation Council (ERC) and the International Liaison Committee on Resuscitation (ILCOR) are also shown.

defibrillation paddles. The position of the centre of the defibrillation pads was recorded by using a grid placed over the chest wall. It was assumed that positions of the pad centre and the paddle centre were anatomically 